\title{
The role of wind catchers in improving people's comfort
}

\author{
N. Valibeig, S. Nasekhian \& S. Tavakoli \\ Department of Architectural and Urban Conservation, \\ Isfahan Art University, Iran
}

\begin{abstract}
Persian architecture used to be an art dealing with people's daily activities. Also, Iranian architects tried to design the traditional architectural elements with respect to climate and environmental considerations. The income, of course, was an architecture inspired by genius and technical knowledge. Among the traditional architectural elements which improved the general comfort was a wind catcher. Today, however, wind catchers have been forgotten. Through using wind catchers the lost comfort can be revived once again and the consumption of non-renewable fuels are decreased. The cold generated by wind catchers in dry climates is quite valuable. So far, extensive studies have been carried out on wind catchers in terms of their form and location on the roofs. Inspired by the idea of wind catchers, the present study has examined the possibility of spreading cold not from the roof but from the floor. The proposed system is based on qanat - a series of well-like vertical shafts, connected by gently sloping tunnels - locally available in dry and hot regions. First, the environmental and climatic conditions of Kerman City, placed in a hot and dry climate, were introduced. Then, the function of wind catchers of two typical houses as case examples was studied: Khane-ye Golab and Khane-ye Movahedi. Finally, an approach was suggested on how a wind catcher may be incorporated in today's buildings to cool them through making minor modifications compatible with modern necessities.
\end{abstract}

Keywords: comfort, qanat, floor-spreading cold, climate, wind catcher. 


\section{Introduction}

Persian architecture has been always a function of peoples' lives [1]. Accordingly, the rationale of designing spaces and architectural elements is the enhancement of the quality of living. That is why architectural elements in old spaces have been designed based on climatic and living conditions. In Iran, with its various climates, traditional architecture has been successful in providing sound and suitable approaches for people to live in comfort [2]. In the traditional architecture of Iran, buildings were built in a way that most possible comfort would be provided without the aid of mechanical (and pollution-generating) equipment [3]. Basically, engineering and technology in Iran has been closely related with science, art, philosophy and religion [4]. In this regard, one of the great (architecturally) engineering achievements in Iran has been wind catchers. Wind catchers have been in use in Iran from the long past. Today, the rate of fossil fuel consumption has surged due to increasing population growth of the world. For this reason, one of the urgent needs of today's modern world seems to be finding ways to decrease or at least optimize fossil fuel consumption. In the past, traditional intelligent architects tried to create a human-based architecture so that they could provide the best possible comfort for people with minimum available possibilities. Today, notwithstanding, it is still possible to save energy consumption and consequent costs considerably through updating traditional approaches.

In the past, Persian intelligent architects managed to design living spaces in a way that the best possible comfort would be available. From the other hand, architectural elements such as wind catchers do not operate by consuming nonrenewable energy; they are economical. Also, wind catchers are environmentally friendly. However, with advancement of technology and industrialization of societies, such architecturally sustainable elements have been put behind. Now, by taking advantage of and being inspired from the past architectural elements it is possible to provide a comfortable atmosphere for today's conditions and, at the same time, to keep the environment green.

The present study aims to answer the following questions:

1. Is there any benefit in using wind catchers for the purpose of cooling today's living spaces effectively?

2. How is it possible to provide a comfortable atmosphere in houses placed in hot and dry climates (like Kerman, Iran) through taking advantage of climatic elements?

3. What is the cooling mechanism of effective wind catchers such as those used in Khane-ye-Golab and Khane-ye-Movahedi (in Kerman)?

This investigation was carried out based on library and field studies. Here, first climatic design in Iran's urban spaces was addressed. Then, the hot and dry climate of Iran was briefly explained. Third, the structure and function of Persian wind catchers as well as materials used in them were examined. Finally, the strong and weak points of heating and cooling systems were examined and the approaches to make them compatible with renewable and green energies 
were suggested so that they can be used in today's Iranian architecture. The cases studied were selected from Kerman - an ancient city with hot and dry climate. In addition, natural energies and the approaches to use them instead of oil-based energies have been addressed. In this study, the energy generated by qanats - a network of tunnels dug underground, connected to each other by a gentle slope has been the main source of natural energy.

\section{Climate and climatic design in Persian architecture}

Adjustment of environmental conditions may be defined as providing physically suitable conditions for people in terms of temperature and light. One of the strong points of Persian traditional architecture has been a climate-oriented design [5]. Determining factors in a climate-oriented design include sunlight angle, latitude, direction and power of wind, availability of water and vegetation [2]. A climate-oriented design, from one hand, decreases the costs of energies consumed in a building and, from the other hand, provides an optimum comfort for the residents. In other words, a climate-oriented design aims to keep or to minimize the energy consumption to generate indoor comfort [6]. In fact, climate, itself, is one of the key factors to form the urban fabrics. Therefore, In order to enhance the comfort of residents and to generate human-centered built environments, a deep knowledge of local climate and its impacts on urban houses is inevitable. There are four climates in Iran: hot and dry; mountainous and cold; temperate and hot and humid.

\subsection{Hot and dry climate}

Major problems which people face with in such climate include burning sunlight, severe hot days, too hot temperature in days and low temperature at nights [7]. As a result of such climatic conditions, provision of optimum comfort for living has been unavoidable [5]. Persian traditional architecture has been compatible with local climates. In hot and dry climate, for example, Persian architects innovated intelligent approaches to design spaces in order to escape from harsh and sever climatic conditions: creating a closed and compressed residential fabric to generate maximum shading; creating shading and shelters on the roofs; making the yards of the houses deeper than the street level outside; applying mud-straw mix (given its bright color); building dome-like roofs; thick walls; building wind catchers and two-layered domes, to name a few. In fact, such a spatial order has been created to generate an optimum comfort needed for residents [8].

\subsection{Climate of Kerman province}

Kerman is in South-East Iran. It is located on margin of Kavir-e-Lut (Lut Desert). There are various local climates in this province because of its different heights and special topography. In fact, Kerman's climate is dry and semitemperate. Kerman is under the influence of regional and extra-regional winds. There is a prevailing wind over the province most of the days [9]. The regional 
climate undergoes considerable changes due to such winds. These winds are mainly of seasonal dry kind conveying dust and sand particles as a result of which regional relative humidity decreases [10].

\section{Thermal limit of comfort}

Wind is a key factor which exchanges temperature, humidity and transfers dust particles. This is important in generating thermal limit of comfort [11]. An area in which humans feel comfortable without using cooling or heating systems - a thermally neutral area - is called as comfort area [5]. As long as the thermal balance between human's body and surrounding ambience is kept, thermal comfort is also kept [11]. In the past, the main aim of constructing residential buildings was creating a comfortable environment for residents and traditional architects tried to minimize the adverse effects of the climatic conditions for people. This was the direct result of a human-based architecture. For example, wind catchers were used to generate thermal comfort [12].

\subsection{Thermal comfort}

Thermal comfort is a state by which both physical and mental comforts are provided. Designers have to generate thermal comfort in terms of indoor climatic conditions. Natural indoor ventilation is directly related to thermal comfort [12].

\section{Wind catchers}

Knowing of the fundamental principles such as thermodynamics, aerodynamics, transfer of temperature, strength of materials and thermal comfort, Persian traditional architects managed to build one of the masterpieces of traditional engineering: wind catchers [13]. Wind catchers are one of the parts of Persian traditional houses, the main function of which is generating thermal comfort. They generate cool air in two ways: moving air and generating evaporative cooling [14]. Wind catchers may be defined as traditional air conditioners operating by using renewable wind energy [15]. They are always erected on summer side of the houses. Usually, it is constructed on the roof of a small room behind the ivan which is connected to wind catcher by a mechanical channel [16]. A wind catcher both traps wind, as the name implies, and directs the stagnant air outdoor [12]. Several factors improve the function of a wind catcher including local temperature, sunlight intensity, maximum variation of day and night temperature and wind direction and velocity. Also, structural feature of wind catchers include height, size of cross section, distribution pattern of channels and the number of wind catching openings (fig. 1). 


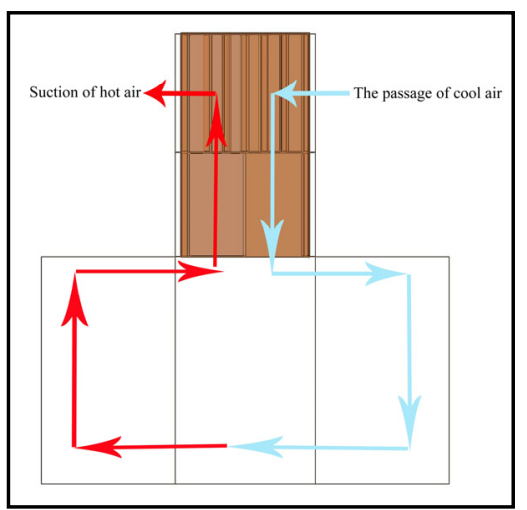

Figure 1: The way cool air enters the wind catcher.

\subsection{Kinds of wind catchers in terms of architectural features}

1. Single-side wind catchers.

2. Double-side wind catchers.

3. Four, six and eight-side wind catchers (figs 2 and 3).

4. Cylindrical wind catchers [17].

Also, some have divided wind catchers into several groups in terms of locations they are currently used such as Yazdi, Kermani or Ardakani wind catchers [18].

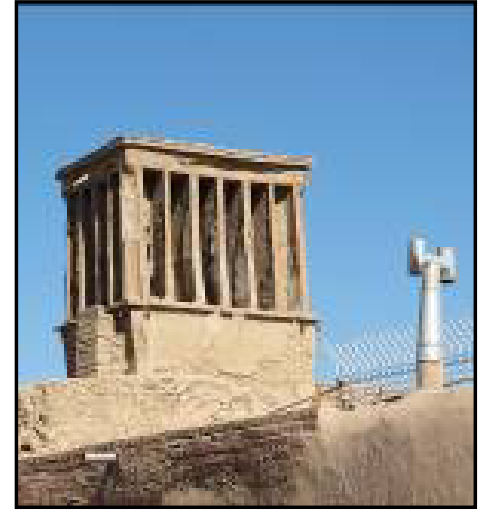

Figure 2: A four-sided wind catcher. Khane-yeGolab.Kerman.



Figure 3: A four-sided wind catcher. Khane-yeMovahedi.Kerman.

The wind catchers studied here - the wind catcher of Khane-ye-Movahedi and wind catcher of Khane-ye-Golab - (both in Kerman) are considered as four sided wind catchers (figs 6 and 7), or Kermani ones. 


\subsection{The structural elements of wind catchers}

Although wind catchers are different in terms of height and size, they are often in cubic or cubo shapes. A wind catcher has several blades in its body. Blades direct wind towards the grid-shaped openings [9]. Wind catchers consists of different parts; some are aesthetic and some functional. They include channels, shelves, base, roof, decorations and materials (figs 4 and 5) [14]. Construction materials of wind catchers include adobe or brick, mud-straw mix, plaster and shourooneh wood (a locally available wood especially resistant against invading termites) [17]. Sometimes, (plaster) mortar in humid regions is also used.

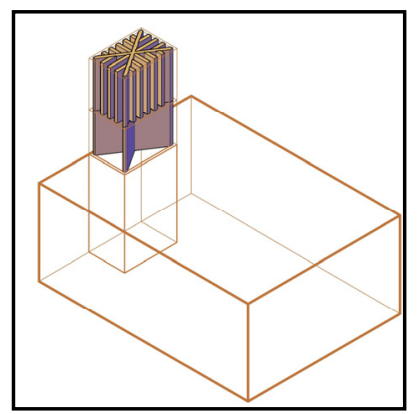

Figure 4: Elements of a wind catcher. Khane-yeGolab.Kerman.



Figure 5: Elements of a wind catcher. Khane-ye Movahedi.Kerman.

\subsection{The problems of wind catchers}

1. In regions with low-speed winds, wind catchers do not work effectively.

2. The openings of wind catchers are potential passage for entering dust particles and pest insects.

3. The amount of cooling energy saved in a wind catcher is limited (due to low special thermal capacity of materials used) and does not suffice for too hot days.

4. Some part of wind trapped in a wind catcher opening escapes out from other openings and do not enter the building [18].

\subsection{Forms of studied wind catchers}

The forms of studied wind catchers are shown in figs 6 and 7.

\subsection{The arrangements of blades of studied wind catchers}

The arrangements of blades of studied wind catchers are shown in figs 8 and 9 . 


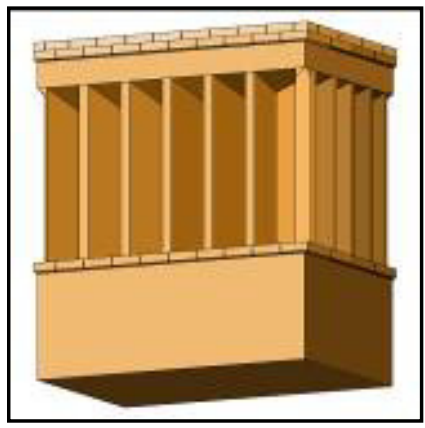

Figure 6: The schematic picture of a four-sided wind catcher. Khane-yeGolab.Kerman

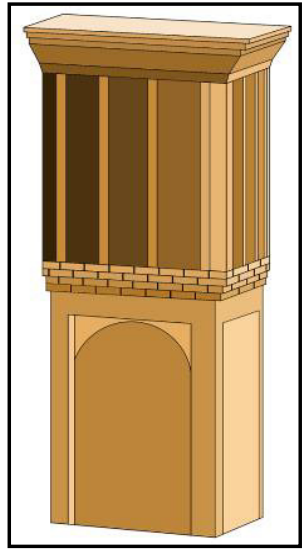

Figure 7: The schematic picture of a four-sided wind catcher. Khane-yeMovahedi.Kerman.

As mentioned before, wind catchers (operating by using clean and renewable wind energy) were used in the past to ventilate or to cool air. During centuries, they were used in hot regions of Iran to cool residential spaces and Ab Anbar (traditional cisterns) effectively without consuming electrical energy [13].

Today, the energy crisis has turned into a serious concern due to the overuse of fossil fuels. Therefore, inventing new approaches to consume renewable energies (such as wind and solar energies) may help a sustainable development [19]. Wind catchers may be considered as important innovations in traditional

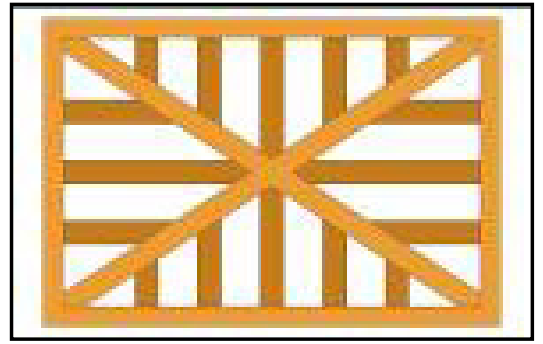

Figure 8: The pattern of blades in the wind catcher of Khane-ye-Golab.

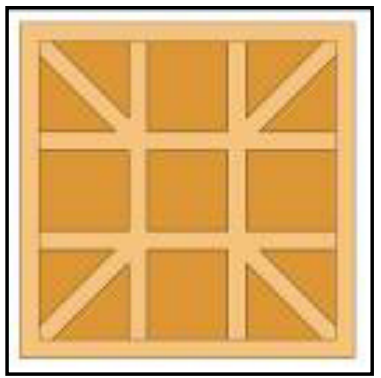

Figure 9: The pattern of blades in the wind catcher of Khaneye-Movahedi. 
architecture of Iran. By reviving Persian wind catchers, it would be possible to not only use renewable energies (and limiting consuming fossil fuels as a result) but also to regain part of the lost identity of traditional cities and villages.

\subsection{Wind}

Variation in air temperature and pressure as well as rotation of the earth results in air movement or blowing wind. A considerable number of cities and villages in hot regions of Iran (such as Zavvare) were planned based on characteristics of local winds. Basically, cities-in hot regions must be planned in a way that wind energy can be exploited effectively [2]. Wind is a key factor in terms of exchanging heat, humidity and transferring suspended dust particles. For this reason, wind qualities may affect comfort of people positively or negatively, both indoor and outdoor [11].

\section{Wind catchers studied}

Today, in order to escape the hot days of summer in hot and dry regions of Iran using electrical coolers has become quite common. However, high costs of electrical energy have made reviving traditional solutions (such as wind catchers) reasonable. The idea of reviving wind catchers is, per se, valuable. Notwithstanding, the problem of current air pollution of cities has challenged the very idea. Therefore, the intelligent solution seems to be modification of traditional wind catchers; that is, supplying the source of cooling not from the surrounding atmosphere, but from the underground air - from qanats. Fig 10 shows the distribution pattern of qanats in the traditional fabric of Kerman.

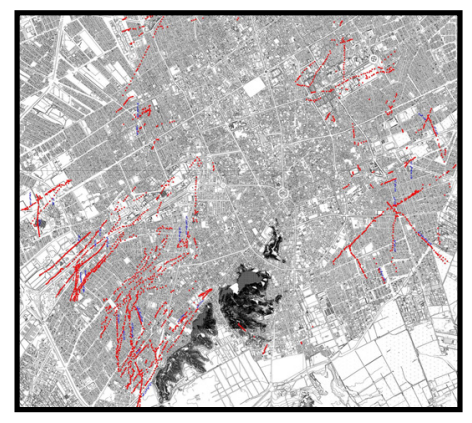

Figure 10: Distribution of Kerman's qanats.

Through creating a network of limited channels underground, a large area of historical places can be benefited from the suggested solution. More specifically, by digging direct or undirected channels in qanat network, it is possible to direct the cool air resulted from moving streams underground towards the dug channels connected to houses (figs 11 and 12). The rationale for the solution is the considerable difference between the underground air temperature and indoor air temperature. This will create a desirable breeze which can be transferred towards the houses. The point, however, is that channels should be dug very carefully so 
that historical buildings are not damaged. In this regard, previously existing wells in the houses can be an advantage. The wells are usually are of two kinds: pumping wells and drainage wells. The first one are, themselves, connected to qanats. But, the second ones can be connected to qanats.

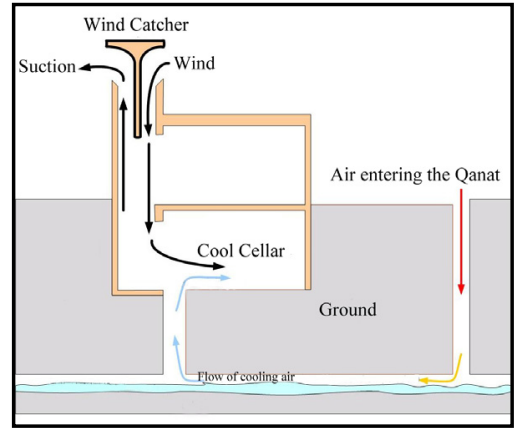

Figure 11: A wind catcher and how it connects to underground water (qanats).

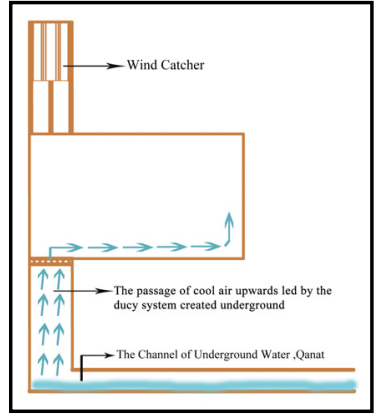

Figure 12: Using an underground channel connected to qanats of the region.

\section{Conclusion}

By reviving the function of wind catchers, it is possible to save the costs of nonrenewable energies. Also, this practice would be a major help in preserving the environment and in managing to consume non-renewable energies. Today, wind catchers can be certainly used to optimize the cooling of residential spaces. The major problem, here, is air pollution of citers preventing the exact copy of architectural form of wind catchers. Therefore, one must take advantage of climatic elements and use them in designing urban architecture. In other words, instead of applying this cooling system directly, its functional concepts should be used along with other underground cooling systems. By designing underground channels connected to the available qanats in the studied historical fabrics, it is possible to provide the pleasant cool air for human's comfort without consuming non clean energies (part 6). The wind catchers used in Khane-ye-Movahedi and Khane-ye-Golab in Kerman - with their four-sided architectural form - from one hand direct the cool and pleasant air into the house and from the other hand push out the indoor stagnant and hot air for other openings of the wind catchers. Through putting the concepts of the traditional architectural elements into practice, it is possible, once again, revive the hidden science in traditional architecture and perpetuate it. This may help the survival of culture and identity of traditional architecture and hand it down to future generations.

\section{References}

[1] Memarian, GH, Persian architecture, Soroush-e-Danesh Publication, Tehran, 2002. 
[2] Ghobadian, V, Climatic study of Persian traditional buildings, Tehran University Publication, Tehran, 2008.

[3] Akrami, Gh, Vaez Maroufi, M. Climatic design; The house pattern in Khour village. Memari Quarterly17-3, 2008.

[4] Farshad, M, The History of Engineering in Iran, Balkh Publication. Tehran, 1997.

[5] Akhtarkavan, M, Adjustment of conditions compatible with Iran climate and ecology, Kalhor Publication, Tehran, 2011.

[6] Watson, D, Labs, K, Climatic Design: Theoretical and Applied Principles of Consuming Energy in Buildings, (translated by Vahid Ghobadian and Mohammad Feiz Mahdavi), Tehran University Publication, Tehran, 2012.

[7] Tavassoli, M, Architecture of hot and dry climates, Marvi Publication, Tehran, 1975.

[8] Tavassoli, M, Urban and architectural construction in hot and dry climates of Iran, Payam Publication, Tehran, 2002.

[9] Tajodini, H, Wind Catchers and their role in Persian architecture in desert regions. The Second Meeting on the History of Persian Architecture and Urbanism, National Cultural Heritage Publication. Vol 5, Tehran, 2004.

[10] Pourahmadi M, Ayatollahi, M, Approaches to revive wind catchers of Yazd based on spatial relationship to summer side of the house, City and Vernacular Architecture, Issue 1, 2011.

[11] Razjouyan M, Wind-supported comfort, Shahid Beheshti University Publication, Tehran, 2007.

[12] McCarthy Consultant Engineers, Badkhan: Physical Considerations of wind in Buildings (translated by Mohammad Ahmadinejad), Khak Publication, Tehran, 2006.

[13] Hashemi H, Masoudi Z, Wind catcher: Persian Engineering Masterpiece in Deserts; An Analysis of Wind Catchers in Southern Khorasan, Khorasan Social-Cultural Studies Quarterly, 2012.

[14] Mahmoudi M, Wind catcher: The symbol of Persian architecture, Yazda Publication Tehran, 2009.

[15] Mahmoudi M, Mofidi, M, How architectural plan of wind catchers decrease ambient temperature, Environmental Science and Technology Quarterly, 13 ${ }^{\text {th }}$ Serial $-1^{\text {st }}$ Issue, 2011.

[16] Abouie, R, Zaker Ameli, L, The appearance of wind catchers in Houses of Dasht-e-Yazd Ardakan, Restoration of Historical and Cultural Works and Buildings, $3^{\text {rd }}$ Issue, 2012.

[17] Bahadorinejad, M, Dehghani, A, Wind catcher; Persian Engineering Masterpiece, Yazda Publication, Tehran, 2012.

[18] Shariatzade, A, The Role of Wind Catchers in Southern Kavir Desert of Yazd Province, The First Meeting on the History of Persian Architecture and Urbanism, Cultural Heritage Publication, Tehran, 1995.

[19] Pourahmadi M, Ayatollahi, M, Approaches to revive wind catchers of Aghda village, Rural Houses and Environment Issue 14, 29, 2012. 